\title{
ESTRUTURA INSTITUCIONAL DA SUSTENTABILIDADE: \\ PANORAMA COMPARATIVO PRELIMINAR BRASIL - FRANÇA
}

\section{Sarah Dounia Lamsaif ${ }^{1}$ \\ Luiz César Ribas ${ }^{2}$ \\ Stella Vannucci Lemos ${ }^{3}$}

RESUMO: A sustentabilidade vem sendo perseguida em todos os segmentos da economia tanto dos países desenvolvidos quanto em desenvolvimento. Especificamente no que diz respeito ao setor rural destes países não poderia ser diferente. O presente trabalho se propõe a analisar e comparar o Brasil e a França em termos das principais semelhanças e diferenças nas suas estruturas institucionais voltadas para a promoção do desenvolvimento rural sustentável. Para tanto, foram utilizados os métodos Dedutivo e Indutivo. Verificou-se que as estruturas institucionais de ambos os países são relativamente semelhantes, muito embora haja especificidades relacionadas às distintas realidades rurais destes países em termos de atividades agropecuárias, florestais, propriedades rurais, dentre outros aspectos. O desenvolvimento rural sustentável desempenha, assim, um papel importante nas políticas nacionais, da França e do Brasil, sendo que a agropecuária, o meio ambiente, as energias, o turismo, a educação e a pesquisa são as principais áreas de sustentabilidade em ambos os países. Pode-se observar que, em geral, um Ministério francês responsabiliza-se, em se tratando de temas vinculados ao desenvolvimento rural sustentável, por uma área de ação mais ampla e menos precisa comparativamente a um Ministério brasileiro. Por fim, alguns

\footnotetext{
${ }^{1}$ Institut National Supérieur des Sciences Agronomiques, de l'Alimentation et de l'Environnement AgroSup Dijon. E-mail: s.lamsaif@agrosupdijon.fr.

2 Departamento de Economia, Sociologia e Tecnologia, Faculdade de Ciências Agronômicas UNESP, Professor Assistente Doutor. E-mail: Icribas@fca.unesp.br.

${ }^{3}$ Faculdade de Ciências Agronômicas - UNESP, Mestranda em Energia na Agricultura. E-mail: svlemos@fca.unesp.br.
} 
temas associados ao tema do desenvolvimento rural sustentável são exclusivamente observados nos Ministérios brasileiros, tais como proteção das florestais tropicais, povos indígenas e biocombustíveis

Palavras-chave: Desenvolvimento rural sustentável. Brasil. França.

\section{INTRODUÇÃO}

Desenvolvimento sustentável é um conceito global, nascido de um consenso entre os representantes de diferentes países e tem como foco principal a resolução dos problemas dos atuais modelos de desenvolvimento. De modo a atingir esse objetivo comum, é necessária a união da "sociedade mundial, a solidaridade entre as diferentes populações do planeta, o diálogo e a cooperação entre civilizações do mundo" (Organização das Nações Unidas, 2013).

O desenvolvimento sustentável é definido como "o desenvolvimento que satisfaz as necessidades do presente sem comprometer a capacidade das gerações futuras satisfazerem as suas próprias necessidades". É um modelo de desenvolvimento economicamente viável, sociologicamente justo e respeitoso com o meio ambiente e os recursos naturais. Os aspectos econômicos, sociológicos e ambientais são os três pilares fundamentais, que se reforçam mutuamente. É um modelo que enfatiza a estabilidade e o equilíbrio entre estes três aspectos ao longo prazo, e que se pensa aos niveis local, nacional e global (Diniz et Bermann, 2012).

No entanto, a implementação de ações concretas em favor do desenvolvimento sustentável varia de um país para outro e até mesmo de uma região para outra. De fato, o desenvolvimento sustentável é encontrar soluções locais dentro de um contexto global (Vedura, 2013).

Políticas de desenvolvimento sustentável, portanto, variam de um país para outro, dependendo dos contextos socioculturais, econômicos e ambientais (Vedura, 2013).

O foco de interesse principal deste trabalho é a discussão e análise da sustentabilidade do meio rural propriamente dito, e isto será realizado objetivamente, num estudo de caso comparativo, em termos de se buscar um melhor entendimento das instituições públicas para a promoção da sustentabilidade no meio rural, tanto 
na França quanto no Brasil.

A sustentabilidade no meio rural leva em consideração varios aspectos desses territorios: as condições geral de vida e o acesso a serviços, a agropecuaria, a silvicultura, o tursimo rural, e a proteção dos recursos naturais e do meio ambiente, considerando as caracteristicas culturais das populações.

A educação também tem um papel fundamental no desenvolvimento sustentável, para promover e compreender a sua importância para os jovens, ou para formar os futuros atores seu estabelecimento. A pesquisa também é uma área importante para o desenvolvimento sustentável, pois gera informações e inovações.

De acordo com o contexto socioeconômico e ambiental do país, do território, questões podem variar: os projetos de desenvolvimento sustentável são diferentes na França e no Brasil.

Políticas para o desenvolvimento rural sustentável são implementadas em todos os níveis. Estamos interessados nesse trabalho as instituições públicas que atuam para a sustentabilidade a nível nacional, na França e no Brasil.

\section{OBJETIVOS}

O objetivo principal deste trabalho é o de relacionar, comparar, compreender e analisar as estruturas institucionais da França e do Brasil para a promoção da sustentabilidade no meio rural.

Como objetivos específicos pretende-se, neste trabalho, apresentar algumas das principais caraterísticas dos setores agropecuário e florestal do Brasil e da França que possam ser enfatizados em termos da busca pelo desenvolvimento rural sustentável destes países.

\section{MATERIAIS E MÉTODOS}

Pretende-se utilizar o método Dedutivo, uma vez que, partindo-se de premissas gerais do material pesquisado, com base em uma cadeia de raciocínio, em ordem decrescente de análise, do geral para o específico, proporcionar a relação, comparação, compreensão e análise das estruturas institucionais da 
França e do Brasil para a promoção da sustentabilidade no meio rural, bem como a identificação de algumas das principais caraterísticas dos setores agropecuário e florestal do Brasil e da França que possam ser enfatizados em termos da busca pelo desenvolvimento rural sustentável destes países (Silva et Menezes, 2005).

Ainda de acordo com as autoras, a natureza da pesquisa é aplicada, visto que objetiva-se gerar conhecimentos para aplicação prática no sentido da solução do problema aqui abordado. A abordagem da pesquisa será qualitativa, uma vez que as informações produzidas serão analisadas indutivamente. Será, ademais, dos tipos, exploratória, descritiva e explicativa, uma vez considerando que se fará uso da pesquisa bibliográfica e documental e análise de experiências relativas ao problema aqui pesquisado, bem como, descrevendo, estabelecendo e identificando relações e principais variáveis dentre as principais características do material de pesquisa aqui trabalhado.

\section{RESULTADOS E DISCUSSÃO}

O Brasil e a França são dois países de tamanho muito diferente: a França tem uma superficie de $551.500 \mathrm{~km}^{2}$ e uma população de quase 62 milhões de pessoas, enquanto que o Brasil conta com 8,5 milhões de $\mathrm{km}^{2}$ e quase 192 milhões de pessoas ${ }^{4}$.

$\mathrm{Na}$ França, a zona rural se define como as pequenas unidades urbanas e as comunas rurais que não permanecem ao espaço urbano. Há vários níveis de "ruralidade", em função da densidade da população e da independência do território ${ }^{5}$.

No Brasil, a zona rural designa as regiões não urbanizadas e destinadas às atividades de agricultura, turismo rural, silvicultura ou conservação ambiental. $A$ zona rural no Brasil apresenta uma população rarefeita, dispersa e dependente dos serviços da sede urbana.

Em 2010, 22,5\% da população francesa, ou seja, 13 milhões de pessoas habitam na área rural, contra 15,64\% da população brasileira, ou seja, 30 milhões de pessoas.

\footnotetext{
${ }^{4}$ A França tem apenas o tamanho do estado de Minas Gerais.

${ }^{5}$ Nesse trabalho, o foco será unicamente a França metropolitania (sem os territórios ultramarinos).
} 
Depreende-se, portanto, das informações acima dispostas, que o desenvolvimento rural sustentável afeta uma parte considerável da população desses dois países. Muitas atividades influenciam a dinâmica das zonas rurais, e são, portanto, levadas em conta na implementação de políticas de desenvolvimento sustentável (França, 2013; Vedura, 2013)

\subsection{AGROPECUÁRIA}

A agricopecuária ocupa um lugar importante em ambos os países. É responsável por uma grande parte de sua economia, proporciona os meios de alimentação para a população, emprega uma parte considerável da população, e afeta os recursos naturais e o meio ambiente. Portanto, essa atividade tem um papel econômico, social e ambiental considerável.

$\mathrm{Na}$ França rural, somente $15,7 \%$ da população trabalha no segmento agropecuário, visto que os setores secundário e terciário da economia francesa empregam uma proporção significativa da população (Agreste, 2013).

No Brasil, mais da metade da população rural (55,3\%) está empregada na agropecuária, que é a principal atividade. Além disso, 84\% da agricultura do país é vinculada à agricultura familiar (Brasil, 2013b).

Em 2012, a França foi considerada o país do continente europeu com a maior produção agrícola, com $18 \%$ da produção agrícola total da Europa. Pouco mais de $50 \%$ das terras francesas são de uso e vocação agrícolas, contra 33\% no Brasil (France, 2013; Instituto Brasileiro de Geografia e Estatística, 2013).

Apesar da agricultura ser um importante segmento econômico em ambos os países, a distribuição das áreas agrícolas, relativamente às demais áreas, é diferente.

Na França, 34\% dessas terras são destinadas a culturas, e 17\% são pastagens permanentes. No Brasil, $26 \%$ das terras agrícolas são pastagens e $7 \%$ são destinadas a culturas permanentes e temporárias (Figura 1). 
Figura 1: Uso das terras na França e no Brasil em 2010 (\% da area total).

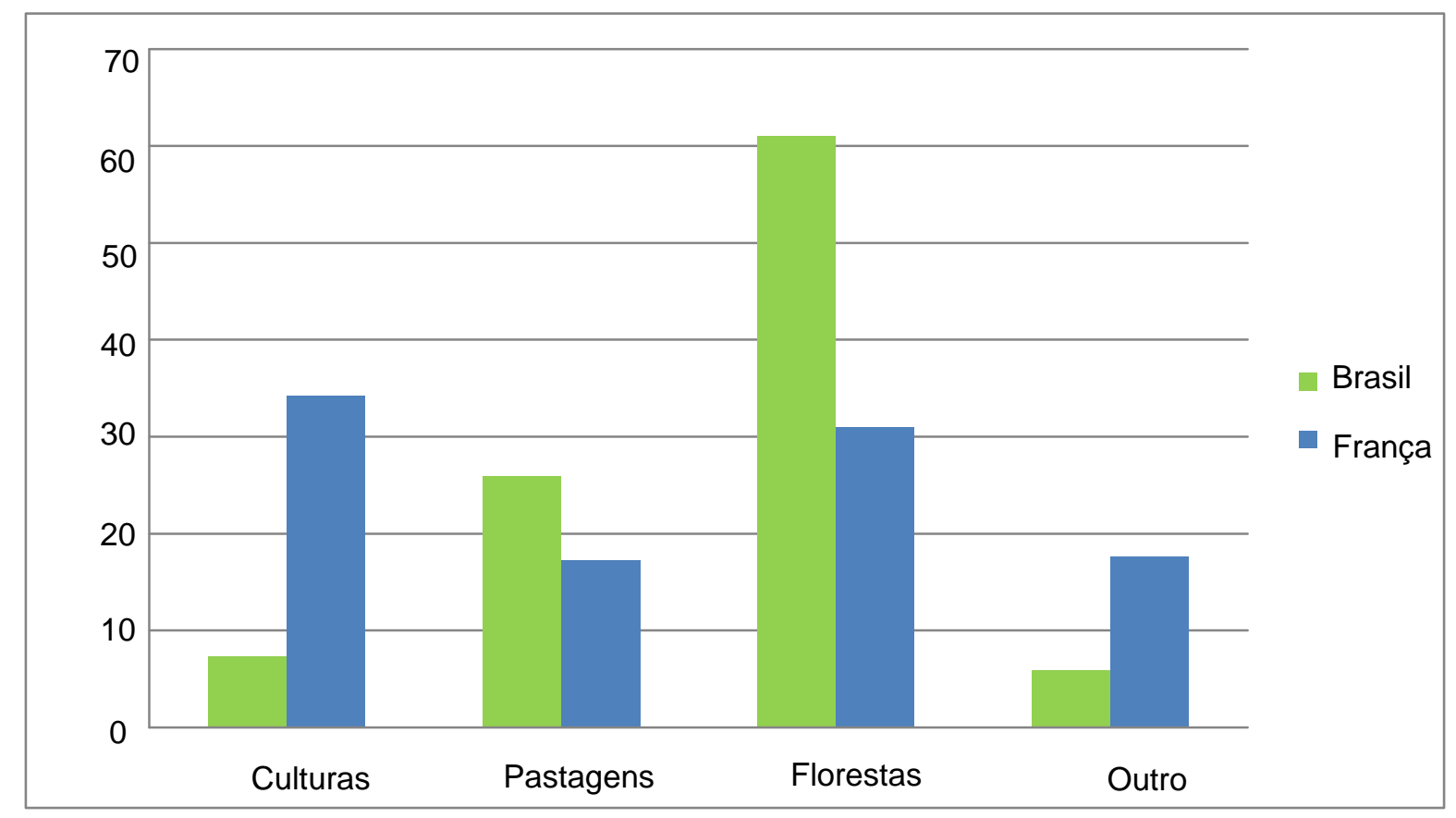

Fonte: Dados da pesquisa

A França destina uma parcela maior de suas terras agrícolas para as culturas que o Brasil, que se concentra em áreas de pastagem para pecuária extensa essencialmente.

As culturas de superfície mais importantes na França são as de cereais (principalmente trigo, milho e cevada), e a uva principalmente para o processamento em vinho.

No Brasil, as principais culturas temporárias são: soja (52,5\% da área colhida em 2011 ) e milho (30\%). O café $(35,4 \%$ da área colhida permanente em culturas do ano de 2009), a laranja, o cacau, a banana e a cana-de-açúcar são as principais culturas permanentes.

A produção de biodiesel é uma questão importante no Brasil, e que é incluída em varios projetos de desenvolvimento sustentável.

Em 2011, as produções animais mais importantes na França são os bovinos (leite: $36 \%$ da produção animal; carne: $28 \%$ ), as aves (14\%) e os porcos $(13 \%)$. A importância da produção de leite pode ser explicada pelos hábitos alimentares dos franceses, que consomem expressivas quantidades de queijo e produtos lácteos (Agreste, 2013; France, 2013). 
No Brasil, $81 \%$ dos animais criados em 2011 são aves, enquanto que $13,6 \%$ são bovinos (Instituto Brasileiro de Geografia e Estatística, 2013).

Assim, os dois países têm uma orientação diferente para a agropecuária. Grande parte disto pode ser reputada às diferenças de recursos naturais (solo e condições climáticas, água, dentre outros aspectos), as oportunidades e os hábitos alimentares.

O tamanho das fazendas também é expressivamente diferente: num país tão grande como o Brasil, as propriedades rurais são de tamanho maior (Figura 2).

Figura 2: Distribuição das áreas das propriedades rurais brasileiras e francesas em função do tamanho em ha (\%).

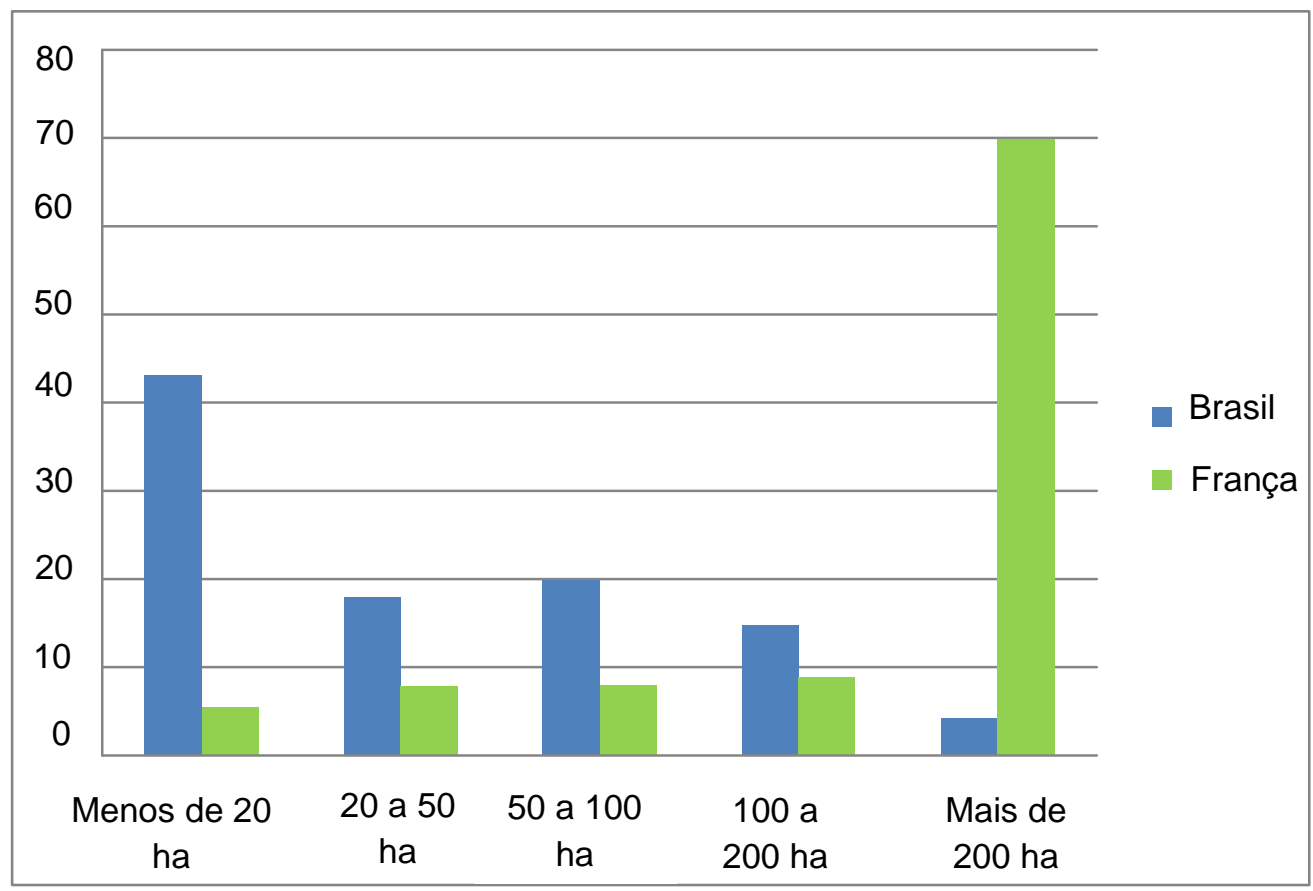

Fonte: Dados da pesquisa

Em termos de produção econômica pode-se dizer que, em 2011, a agropecuária na França participou com $2 \%$ do PIB francês, enquanto que a atropecuária no Brasil participou com 6\% do PIB brasileiro (France, 2013; Instituto Brasileiro de Geografia e Estatística, 2013).

A agropecuária aparece como uma atividade fundamental em áreas rurais, tanto no Brasil quanto na França. A agropecuária emprega nestes dois países, ainda, uma grande proporção da população, participando de forma significativa 
para ambas as economias nacionais. Além disto, os setores agropecuários, francês e brasileiro, impactam fortemente o meio ambiente, a paisagem e os recursos naturais.

Os setores agropecuários destes países são, muito embora com diferentes objetivos e desafios ${ }^{6}$, cruciais para todo e qualquer projeto de desenvolvimento rural sustentável.

\subsection{SILVICULTURA}

As florestas ocupam $61 \%$ do território brasileiro e $31 \%$ do território francês (Instituto Brasileiro de Geografia e Estatística, 2013; Agreste, 2013).

Em ambos os países o setor florestal apresenta funções fundamentais, como a produção de madeira e produtos não madeireiros, a proteção de solo e recursos hídricos, a conservação da biodiversidade e os serviços sociais. Também tem um papel considerável nas mudanças climáticas.

Contudo, os contextos são bem diferentes nos dois países e, portanto, os objetivos da sustentabilidade florestal são diferentes.

Neste sentido, verifique-se, a título exemplificativo, que devido à grande área que as florestas ocupam (mais da metade do território), o manejo florestal sustentável é um aspecto fundamental da sustentabilidade no Brasil.

Além disso, o desmatamento é um problema que o país enfrenta. Note-se que, na Amazônia, 17\% das florestas vinham sendo desmatados a cada ano, enquanto que as florestas francesas vêm crescendo a uma taxa de 0,3\% ao ano (Institut National de la statistique et des études économiques, 2103; Brasil, $2013 \mathrm{~g}$ ).

Outra peculiaridade do Brasil em relação à França é a existência dos povos indígenas, que vivem dos recursos da floresta. Este aspecto desempenha um papel significativo na implantação de projetos de desenvolvimento sustentável e das políticas florestais, especialmente na Amazônia (Brasil, $2013 \mathrm{~g}$ ).

O manejo florestal sustentável pode ser visto, em síntese, como fundamental em ambos os países, mas com questões diferentes.

\footnotetext{
${ }^{6}$ Por exemplo, na agropecuária brasileira há temas de elevada recorrência, tais como, agricultura familiar e bioenergia, enquanto que tais temas são quase inexistentes na França.
} 


\subsection{ESTRUTURA POLÍTICO-INSTITUCIONAL NA ÁREA AMBIENTAL}

Os sistemas políticos existentes tanto na França quanto no Brasil são diferentes.

O Presidente da República Francesa, por exemplo, é nomeado como Chefe de Estado, havendo também a figura de um Primeiro-ministro, que é denominado Chefe de Governo (France, 2013 b).

Estas condições políticas não existem no Brasil, onde o sistema político é presidencialista. O Presidente da República é tanto o Chefe do Estado quanto o Chefe do Governo.

Contudo, a organização das instituições públicas para o desenvolvimento sustentável, notadamente no que concerne ao meio rural, é quase o mesmo na França e no Brasil.

Os Ministérios são peculiaries em ambos os países ${ }^{7}$. O Brasil tem 24 ministérios $^{8}$, dos quais 9 promovem o desenvolvimento rural sustentável. Cada ministério tem uma área específica de intervenção, mas há muitas relações de cooperação entre eles, notadamente na área ambiental (Tabela 1).

Todavia, conforme DIRECTION DE L'INFORMATION LÉGALE ET ADMINISTRATIVE (2013), a França tem 21 ministérios, dos quais 6 são envolvidos na promoção da sustentabilidade em áreas rurais do território francês (Tabela 2).

Além disto, existem instituições públicas (por exemplo, instituições de pesquisa) que trabalham em consonância com os Ministérios relacionados nas Tabelas 1 e 2, primordialmente para fornecer informações e possibilitar a implantação efetiva das políticas de desenvolvimento rural sustentável.

Outra semelhança entre os dois países é a existência de instituições e serviços públicos "descentralizados"9 que são utilizados para monitorar a implementação de políticas federais mais proximamente, bem como para adaptá-

\footnotetext{
${ }^{7}$ Ministérios são instituições nacionais responsáveis pela definição e implantação de políticas.

${ }^{8}$ Fonte: http://www2.planalto.gov.br/presidencia/ministros/ministerios

${ }^{9}$ Secretarias e órgãos estaduais e municipais no caso brasileiro, e organizações departamentais, no caso francês.
} 
las aos territórios locais para uma melhor eficiência (Brasil, 2013; France, 2013 b).

Apesar de uma organização global semelhante, existem muitas diferenças entre os sistemas institucionais, brasileiro e francês, voltados para o desenvolvimento rural sustentável. A identificação das diferenças e semelhanças, em termos das distintas realidades rurais destes países, poderia ser oportunamente trabalhada.

Tabela 1: Instituções federais e o desenvolvimento rural sustentável no Brasil.

\begin{tabular}{|c|c|c|c|c|}
\hline Ministério & $\begin{array}{l}\text { Ano de } \\
\text { criação }\end{array}$ & Objetivos/Missão & Público alvo & $\begin{array}{c}\text { Principais setores } \\
\text { de intervenção }\end{array}$ \\
\hline $\begin{array}{l}\text { Agricultura } \\
\text { Pecária e } \\
\text { Abastec. } \\
\text { (MAPA) }\end{array}$ & 1860 & $\begin{array}{l}\text { Segurança alimentar; } \\
\text { Agroenergia; Produção } \\
\text { não alimentar e não } \\
\text { energética. }\end{array}$ & $\begin{array}{c}\text { Agronegócios: } \\
\text { Pequenos, médios e } \\
\text { grandes produtores }\end{array}$ & $\begin{array}{c}\text { Agroenergias; } \\
\text { Produção Integrada; } \\
\text { Orgânicos; } \\
\text { Conservação do solo } \\
\text { e da água; Florestas } \\
\text { plantadas. }\end{array}$ \\
\hline $\begin{array}{l}\text { Desenv. } \\
\text { Agrário } \\
\text { (MDA) }\end{array}$ & 1999 & $\begin{array}{l}\text { Aumento e proteção da } \\
\text { renda; Inovação e } \\
\text { tecnologia; Aumento da } \\
\text { produção de alimentos. }\end{array}$ & Agricultura familiar & $\begin{array}{c}\text { Geração de Renda e } \\
\text { Agregação de Valor; } \\
\text { Assistência Técnica e } \\
\text { Extensão Rural; } \\
\text { Financiamento e } \\
\text { Proteção da } \\
\text { Produção; } \\
\text { Reordenamento } \\
\text { Agrário; } \\
\text { Desenvolvimento } \\
\text { territorial. }\end{array}$ \\
\hline
\end{tabular}




\begin{tabular}{|c|c|c|c|c|}
\hline $\begin{array}{c}\text { Meio } \\
\text { Ambiente } \\
\text { (MMA) }\end{array}$ & 1992 & \begin{tabular}{|} 
Conhecimento, proteção \\
e recuperação do meio \\
ambiente; Uso \\
sustentável dos \\
recursos naturais; \\
Valorização dos \\
serviços ambientais.
\end{tabular} & Diversos & \begin{tabular}{|c|} 
Água; Áreas \\
protegidas; Biomas; \\
Clima; \\
Desenvolvimento \\
Rural; Florestas; \\
Gestão territorial; \\
Governança \\
ambiental; \\
Responsabilidade \\
socio-ambiental.
\end{tabular} \\
\hline $\begin{array}{c}\text { Pesca e } \\
\text { Aquicultura } \\
\text { (MPA) }\end{array}$ & 2003 & $\begin{array}{c}\text { Diminuição do grau de } \\
\text { analfabetismo; Aumento } \\
\text { do nivel de estudos, do } \\
\text { conhecimento da } \\
\text { legislação, e da } \\
\text { participação dos } \\
\text { pescadores nas } \\
\text { organizações sociais. }\end{array}$ & $\begin{array}{l}\text { Agricultura familiar, } \\
\text { pequenos produtores. }\end{array}$ & Pesca artesanal \\
\hline $\begin{array}{c}\text { Desenv. } \\
\text { Social e } \\
\text { Combate a } \\
\text { fome } \\
\text { (MDS) }\end{array}$ & 2004 & $\begin{array}{c}\text { Diminuição da probreza, } \\
\text { combate à fome; } \\
\text { Promção da inclusão } \\
\text { social; Segurança } \\
\text { alimentar; Assistência } \\
\text { integral }\end{array}$ & População carente & \begin{tabular}{|c|} 
Produção e \\
distribuição de \\
alimentos; Agricultura \\
familiar; \\
Desenvolvimento e \\
Educação
\end{tabular} \\
\hline $\begin{array}{c}\text { Minas e } \\
\text { Energias } \\
\text { (MME) }\end{array}$ & 1960 & $\begin{array}{l}\text { Promover a inclusão } \\
\text { social; Garantir preços } \\
\text { competitivos e } \\
\text { qualidade; Produzir } \\
\text { bioenergias a partir de } \\
\text { diferentes fontes e } \\
\text { regiões diversas. }\end{array}$ & Diversos & $\begin{array}{c}\text { Bioenergias; Energias } \\
\text { renováveis. }\end{array}$ \\
\hline
\end{tabular}




\begin{tabular}{|c|c|c|c|c|}
\hline $\begin{array}{l}\text { Ciência, } \\
\text { Tecnol. e } \\
\text { Inovação } \\
\text { (MCT) }\end{array}$ & 1985 & $\begin{array}{c}\text { Gerar conhecimento, } \\
\text { tecnologia e inovação } \\
\text { para a promoção do } \\
\text { desenvolvimento } \\
\text { sustentavel. }\end{array}$ & $\begin{array}{c}\text { Atores sociais e } \\
\text { institucionais, } \\
\text { instituições de } \\
\text { pesquisa, } \\
\text { instituições de } \\
\text { ensino, empresas. }\end{array}$ & $\begin{array}{c}\text { Agronegócios; } \\
\text { Biocombustíveis, } \\
\text { Mudanças } \\
\text { climáticas; } \\
\text { Biotecnologia. }\end{array}$ \\
\hline Turismo & 2003 & $\begin{array}{c}\text { Desenvolver o turismo } \\
\text { como uma atividade } \\
\text { econômica } \\
\text { sustentável. }\end{array}$ & Diversos & Turismo rural \\
\hline $\begin{array}{c}\text { Educação } \\
\text { (MEC) }\end{array}$ & 1930 & $\begin{array}{l}\text { Promover um ensino } \\
\text { de qualidade. }\end{array}$ & $\begin{array}{l}\text { Estudantes; } \\
\text { Professores; } \\
\text { Instituições de } \\
\text { Ensino }\end{array}$ & $\begin{array}{l}\text { Educação superior; } \\
\text { Educação básica. }\end{array}$ \\
\hline
\end{tabular}

Fonte: Dados da pesquisa

Tabela 2: Instituções federais e o desenvolvimento rural sustentável na França

\begin{tabular}{|c|c|c|c|c|}
\hline Ministério & $\begin{array}{l}\text { Ano de } \\
\text { criação }\end{array}$ & Objetivos / Missão & Publico alvo & $\begin{array}{c}\text { Setores de } \\
\text { intervenção }\end{array}$ \\
\hline $\begin{array}{c}\text { Agricultura } \\
\text { e } \\
\text { Florestas }\end{array}$ & 1881 & $\begin{array}{l}\text { Desenvolvimento } \\
\text { agrícola } \\
\text { economicamente e } \\
\text { ecologicamente } \\
\text { intensivo } \\
\end{array}$ & $\begin{array}{c}\text { Agricultores; } \\
\text { Estudantes; } \\
\text { Pesquisadores }\end{array}$ & $\begin{array}{c}\text { Educação; Meio } \\
\text { Ambiente; } \\
\text { Florestal/Madeireiro; } \\
\text { Social; Pesquisa e } \\
\text { Desenvolvimento } \\
\end{array}$ \\
\hline $\begin{array}{l}\text { Desenv. } \\
\text { Sustent., } \\
\text { Ecologia e } \\
\text { Meio } \\
\text { Ambiente }\end{array}$ & 2007 & $\begin{array}{c}\text { Fornecer informações; } \\
\text { Ajudar os atores nas } \\
\text { suas ações a favor do } \\
\text { desenvolvimento } \\
\text { sustentável }\end{array}$ & Diversos & $\begin{array}{l}\text { Mudanças climaticas; } \\
\text { Biodiversidade; } \\
\text { Prevenção dos riscos; } \\
\text { Energia; Minas }\end{array}$ \\
\hline $\begin{array}{l}\text { Artesanato } \\
\text { e Turismo }\end{array}$ & 2012 & $\begin{array}{c}\text { Promover o ecoturismo } \\
\text { no meio rural }\end{array}$ & Diversos & $\begin{array}{c}\text { Ecoturismo; Turismo } \\
\text { sustentável }\end{array}$ \\
\hline
\end{tabular}




\begin{tabular}{|c|c|c|c|c|}
\hline $\begin{array}{l}\text { lgualdade } \\
\text { dos } \\
\text { Territórios }\end{array}$ & 1967 & $\begin{array}{c}\text { Favorecer o } \\
\text { Desenvolvimento } \\
\text { Econômico; } \\
\text { Sensibilização ao } \\
\text { Desenvolvimento } \\
\text { Sustentável }\end{array}$ & Diversos & $\begin{array}{c}\text { Mudanças climáticas; } \\
\text { Ordenamento do } \\
\text { Território, Eco- } \\
\text { construções }\end{array}$ \\
\hline $\begin{array}{l}\text { Educação } \\
\text { Nacional }\end{array}$ & 1828 & $\begin{array}{c}\text { Educação de qualidade } \\
\text { para todos }\end{array}$ & $\begin{array}{c}\text { Educação basica } \\
\text { pública. }\end{array}$ & Educação ambiental \\
\hline $\begin{array}{c}\text { Ensino } \\
\text { Superior e } \\
\text { Pesquisa }\end{array}$ & 1901 & $\begin{array}{l}\text { Educação de nível } \\
\text { pleno, Inovação e } \\
\text { Pesquisa Científica }\end{array}$ & $\begin{array}{c}\text { Ensino superior } \\
\text { público; Orgãos de } \\
\text { Pesquisa }\end{array}$ & $\begin{array}{c}\text { Ciências e } \\
\text { Tecnologia; Economi }\end{array}$ \\
\hline
\end{tabular}

Fonte: Dados da Pesquisa.

Das Tabelas 1 e 2 pode-se depreender que o tema do desenvolvimento rural sustentável pode ser encontrado em vários Ministérios, de maneira mais ou menos importante, intensa ou expressiva, dependendo da área específica de atuação de cada Ministério.

O Ministério da Agricultura, no caso brasileiro, é o mais antigo, tendo sido fundado em 1860. Com o tempo, outros Ministérios no Brasil que relacionados com o desenvolvimento rural sustentável (agricultura, abastecimento, pecuária, pesca, meio ambiente e os recursos naturais, etc.) surgiram.

O Ministério do Meio Ambiente, por exemplo, foi criado em 1992, provavelmente como resultado da Conferência do Rio sobre Desenvolvimento Sustentável.

Os Ministérios brasileiros mais diretamente envolvidos com a promoção da sustentabilidade do setor rural do país são o MAPA, o MDA, o MMA e o MCT.

Em se tratando de meio ambiente, e mesmo da sustentabilidade do meio rural, pode-se verificar que geralmente um determinado assunto depende de ação de vários Ministérios.

Este é o caso, por exemplo, da agricultura, visto que dois Ministérios são diretamente dedicados a este tema (MAPA e MDA). Por outro lado, é possível mencionar as florestas, que dependem do MAPA, do MDA e do MMA.

$\mathrm{Na}$ verdade, é relativamente difícil distinguir as ações em alguns setores, tais como a agricultura. É também difícil avaliar e segmentar os impactos sobre o 
meio ambiente, por exemplo.

Da mesma forma, na França o desenvolvimento rural sustentável desempenha um papel importante na política atual. Como no Brasil, os Ministérios da Agricultura e Educação, duas áreas "chave", são os mais antigos. O Ministério do Desenvolvimento Sustentável, entretanto, surgiu recentemente (2007).

O desenvolvimento rural sustentável desempenha, assim, um papel importante nas políticas nacionais, da França e do Brasil, sendo que a agropecuária, o meio ambiente, as energias, o turismo, a educação e a pesquisa são as principais áreas de sustentabilidade em ambos os países.

De toda sorte, um fato interessante deve ser destacado. A história institucional da França é muito mais antiga do que a do Brasil. No entanto, um Ministério francês especializado nas questões do meio ambiente e da ecologia apareceu 15 anos mais tarde na França que no Brasil.

Por fim, seria interessante traçar um paralelo entre as semelhanças existentes tanto nos Ministérios franceses quanto brasileiros com respeito a diferentes pontos do desenvolvimento rural sustentável (Tabela 4).

Tabela 4. Ministérios responsáveis dos diferentes assuntos da sustentabilidade rural na França e no Brasil.

\begin{tabular}{|c|c|c|}
\hline Assunto & $\begin{array}{c}\text { Ministérios brasileiros } \\
\text { responsáveis }\end{array}$ & $\begin{array}{c}\text { Ministérios franceses } \\
\text { responsáveis }\end{array}$ \\
\hline $\begin{array}{c}\text { Agroenergias e energias } \\
\text { renováveis }\end{array}$ & MAPA e MME & $\begin{array}{c}\text { Min. do Desenv. Sustentável, } \\
\text { da Ecologia e Energias }\end{array}$ \\
\hline Agropecuária & MAPA; MDA e MDS & Min. da Agricultura e Floresta \\
\hline Floresta, Madeira & MMA e MAPA & Min. da Agricultura e Floresta \\
\hline Pesca & MPA & $\begin{array}{c}\text { Min. da Agricultura e Floresta; } \\
\text { desenv. sustentável, Ecologia e } \\
\text { Energias }\end{array}$ \\
\hline Turismo Rural & Min. do turismo & $\begin{array}{c}\text { Min. do Comércio, Artesanato e } \\
\text { Turismo }\end{array}$ \\
\hline Água e Solo & MMA e MAPA & $\begin{array}{c}\text { Min. do Desenvolv. } \\
\text { sustentaáel, Ecologia e } \\
\text { Energias }\end{array}$ \\
\hline
\end{tabular}




\section{$\begin{array}{ll}\text { Periódica Eletrânica } & \text { ISSN 1980-0827 }\end{array}$}

\begin{tabular}{|c|c|c|}
\hline Clima e Ar & MMA & $\begin{array}{c}\text { Min. do Desenv. Sustentável, } \\
\text { Ecologia e Energias; Min. da } \\
\text { Igualdade dos Territórios }\end{array}$ \\
\hline Minas & MME & $\begin{array}{c}\text { Min. do Desenv. Sustentável, } \\
\text { Ecologia e Energias }\end{array}$ \\
\hline Biodiversidade & MMA & $\begin{array}{c}\text { Min. do Desenv. Sustentável, } \\
\text { Ecologia e Energias }\end{array}$ \\
\hline $\begin{array}{c}\text { Recuperação de Áreas } \\
\text { Degradadas }\end{array}$ & MMA, MAPA e MDA & $\begin{array}{c}\text { Min. do Desenv. Sustentável, } \\
\text { Ecologia e Energias }\end{array}$ \\
\hline $\begin{array}{c}\text { Educação, Tecnologia e } \\
\text { Pesquisa Agrícola e } \\
\text { Ambiental }\end{array}$ & $\begin{array}{c}\text { MAPA, MDA, MMA, MDS, MEC } \\
\text { e MCT }\end{array}$ & $\begin{array}{l}\text { Min. da Agricultura e Floresta; } \\
\text { Min. da Educação Nacional; } \\
\text { Min. do Ensino Superior e da } \\
\text { Pesquisa }\end{array}$ \\
\hline
\end{tabular}

Fonte: Dados da pesquisa.

Pode-se observar da Tabela 4 que, em geral, um Ministério francês responsabiliza-se, em se tratando de temas vinculados ao desenvolvimento rural sustentável, por uma área de ação mais ampla e menos precisa comparativamente a um Ministério brasileiro.

Assim, no Brasil, diversos Ministérios podem ser associados a um mesmo tema da sustentabilidade rural.

Neste escopo, a recuperação de áreas degradadas é bastante ilustrativo. Isto porque, 03 Ministérios brasileiros são diretamente relacionados, enquanto apenas um Ministério francês é associado a este tema em específico.

A Agropecuária, por seu turno, apresenta 02 Ministérios associados ao tema no Brasil, quais sejam, o MAPA e o MDA $^{10}$.

$\mathrm{Na}$ França, em contraste, o tema da Educação é gerido por 02 Ministérios: o da Educação básica e o do Ensino superior, sendo este último também responsável pela pesquisa.

No Brasil, a pesquisa e a educação são abordados separadamente em 02 Ministérios distintos.

Alguns temas associados ao tema do desenvolvimento rural sustentável são

\footnotetext{
${ }^{10}$ Observe-se que, no caso brasileiro, o tema específicoda Agricultura Familiar surgiu mais de um século após a criação de um Ministério da Agricultura.
} 
exclusivamente observados nos Ministérios brasileiros, tais como proteção das florestais tropicais, povos indígenas e biocombustíveis.

\section{CONCLUSÃO}

O desenvolvimento rural sustentável afeta uma parte considerável da população desses dois países. Muitas atividades influenciam a dinâmica das zonas rurais, e são, portanto, levadas em conta na implantação de políticas de desenvolvimento sustentável.

A agropecuária ocupa um lugar importante em ambos os países. É responsável por uma grande parte de sua economia, proporciona os meios de alimentação para a população, emprega uma parte considerável da população, e afeta os recursos naturais e o meio ambiente. Portanto, essa atividade tem um papel econômico, social e ambiental considerável.

Apesar da agricultura ser um importante segmento econômico em ambos os países, a distribuição das áreas agrícolas, relativamente às demais áreas, é diferente. Na França, 34\% dessas terras são destinadas a culturas, e 17\% são pastagens permanentes. No Brasil, $26 \%$ das terras agrícolas são pastagens e $7 \%$ são destinadas a culturas permanentes e temporárias.

A agropecuária aparece como uma atividade fundamental em áreas rurais, tanto no Brasil quanto na França. A agropecuária emprega nestes dois países, ainda, uma grande proporção da população, participando de forma significativa para ambas as economias nacionais. Além disto, os setores agropecuários, francês e brasileiro, impactam fortemente o meio ambiente, a paisagem e os recursos naturais.

Os setores agropecuários destes países são, muito embora com diferentes objetivos e desafios, cruciais para todo e qualquer projeto de desenvolvimento rural sustentável.

Em ambos os países o setor florestal apresenta funções fundamentais, como a produção de madeira e produtos não madeireiros, a proteção de solo e recursos hídricos, a conservação da biodiversidade e os serviços sociais. Também tem um papel considerável nas mudanças climáticas.

O manejo florestal sustentável pode ser visto, em síntese, como 
fundamental em ambos os países, mas com questões diferentes.

Os sistemas políticos existentes tanto na França quanto no Brasil são diferentes. Contudo, a organização das instituições públicas para o desenvolvimento sustentável, notadamente no que concerne ao meio rural, é quase o mesmo na França e no Brasil.

Os Ministérios são peculiaries em ambos os países. Todavia, a França tem 21 ministérios, dos quais 6 são envolvidos na promoção da sustentabilidade em áreas rurais do território francês. O Brasil tem 24 ministérios, dos quais 9 promovem o desenvolvimento rural sustentável. Cada ministério tem uma área específica de intervenção, mas há muitas relações de cooperação entre eles, notadamente na área ambiental.

Além disto, existem instituições públicas (por exemplo, instituições de pesquisa) que trabalham em consonância com os Ministérios brasileiros e franceses, primordialmente para fornecer informações e possibilitar a implantação efetiva das políticas de desenvolvimento rural sustentável.

Outra semelhança entre os dois países é a existência de instituições e serviços públicos "descentralizados" que são utilizados para monitorar a implementação de políticas federais mais proximamente, bem como para adaptálas aos territórios locais para uma melhor eficiência.

O tema do desenvolvimento rural sustentável pode ser encontrado em vários Ministérios, de maneira mais ou menos importante, intensa ou expressiva, dependendo da área específica de atuação de cada Ministério.

O desenvolvimento rural sustentável desempenha, assim, um papel importante nas políticas nacionais, da França e do Brasil, sendo que a agropecuária, o meio ambiente, as energias, o turismo, a educação e a pesquisa são as principais áreas de sustentabilidade em ambos os países.

Pode-se observar que, em geral, um Ministério francês responsabiliza-se, em se tratando de temas vinculados ao desenvolvimento rural sustentável, por uma área de ação mais ampla e menos precisa comparativamente a um Ministério brasileiro.

Alguns temas associados ao tema do desenvolvimento rural sustentável são exclusivamente observados nos Ministérios brasileiros, tais como proteção das florestais tropicais, povos indígenas e biocombustíveis. 


\section{$\begin{array}{ll}\text { Periódica Eletrânica } & \text { ISSN 1980-0827 }\end{array}$}

\section{REFERÊNCIAS}

AGRESTE. La statistique, I'evaluation et la prospective agricole. Disponível em: $<$ http://agreste.agriculture.gouv.fr/> Acesso: 25.09.2013.

BRASIL. Ministérios (ordem alfabética). Disponível em:< http://www2.planalto.gov.br/presidencia/ministros/ministerios> Acesso: 25.09.2013.

. Ministério da Agricultura, Pecuária e Abastecimento. Disponível em:< http://www.agricultura.gov.br/> Acesso: 25.09.2013.

- Ministério da Ciência, Tecnologia e Inovação. Disponível em:< http://www.mct.gov.br/> Acesso: 25.09.2013.

Ministério do Desenvolvimento Agrário. Disponível

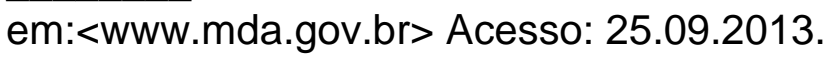

- Ministério do Desenvolvimento Social e Combate à Fome. Disponível em:< http://www.mds.gov.br/> Acesso: 25.09.2013.

Acesso: 25.09.2013.

Ministério da Educação. Disponível em:< http://www.mec.gov.br/>

Ministério do Meio

Ambiente. Disponível em:< http://www.mma.gov.br/> Acesso: 25.09.2013

Ministério das Minas e Energias. Disponível em:< http://www.mme.gov.br/mme> Acesso: 25.09.2013.

Ministério da Pesca e Aquicultura. Disponível em:< http://www.mpa.gov.br/> Acesso: 25.09.2013.

Ministério do Turismo. Disponível

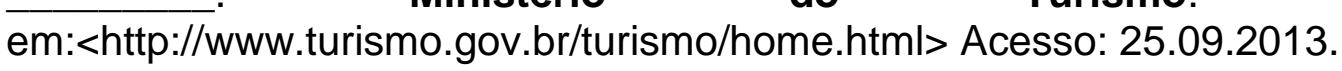

DINIZ, E. M. et BERMANN, C. Economia verde e sustentabilidade. Estudos Avançados [online]. 2012, vol. 26, n.7 4, pp. 323-330. ISSN 0103-4014. http://dx.doi.org/10.1590/S0103-40142012000100024.

DIRECTION DE L'INFORMATION LÉGALE ET ADMINISTRATIVE. Mon Vie Publique. Disponível em:< http://www.vie-publique.fr/> Acesso: 25.09.2013.

FRANCE. La France Agricole, « Etiquetage environnemental des produits, Premières expérimentations en juillet » (22/10/2010). Disponível em:< http://www.lafranceagricole.fr/actualite-agricole/etiquetage-environnemental-desproduits-premieres-experimentations-en-juillet-33856.html. Acesso: 25.09.2013.

Portail du gouvernement. Disponível em:<http://www.gouvernement.fr/> Acesso: 25.09.2013. 
IBGE. Instituto Brasileiro de Geografia e Estatística. Disponível em<http://www.ibge.gov.br/home/> Acesso: 25.09.2013.

INSEE. Institut National de la statistique et des études économiques. Disponível em:< http://www.insee.fr/fr/> Acesso> 25.09.2013.

ONU. Declaração de Joanesburgo sobre Desenvolvimento Sustentável. Das nossas origens ao futuro. Organização das Nações Unidas. Disponível em:< http://www.onu.org.br/rio20/img/2012/07/unced2002.pdf> Acesso: 25.09.2013.

SILVA, E. L. et MENEZES, E. M. Metodologia da pesquisa e elaboração de dissertação/Edna Lúcia da Silva, Estera Muszkat Menezes. - 4. ed. rev. atual. Florianópolis: UFSC, 2005. 138p.

VEDURA. Historique du développement durable. Disponível em :< http://www.vedura.fr/developpement-durable/cadre/historique>. Acesso: 25.09.2103. 